\title{
Salting-Out Assisted Liquid-Liquid Extraction Combined with HPLC for Quantitative Extraction of Trace Multiclass Pesticide Residues from Environmental Waters
}

\author{
Yosef Alemayehu',2, Teshome Tolcha², Negussie Megersa2* \\ ${ }^{1}$ Department of Environmental Science, College of Agriculture and Environmental Sciences, University of South Africa, \\ Pretoria, South Africa \\ ${ }^{2}$ Department of Chemistry, College of Natural and Computational Sciences, Addis Ababa University, \\ Addis Ababa, Ethiopia \\ Email: ^megersane@yahoo.com, ^negussie.megersa@gmail.com, ^negussie.megersa@aau.edu.et
}

How to cite this paper: Alemayehu, Y., Tolcha, T. and Megersa, N. (2017) Salting-Out Assisted Liquid-Liquid Extraction Combined with HPLC for Quantitative Extraction of Trace Multiclass Pesticide Residues from Environmental Waters. American Journal of Analytical Chemistry, 8, 433448 .

https://doi.org/10.4236/ajac.2017.87033

Received: March 30, 2017

Accepted: July 1, 2017

Published: July 4, 2017

Copyright $\odot 2017$ by authors and Scientific Research Publishing Inc. This work is licensed under the Creative Commons Attribution International License (CC BY 4.0).

http://creativecommons.org/licenses/by/4.0/

(c) (i) Open Access

\begin{abstract}
In this study, salting-out assisted liquid-liquid extraction combined with high performance liquid chromatography diode array detector (SALLE-HPLC-DAD) method was developed and validated for simultaneous analysis of carbaryl, atrazine, propazine, chlorothalonil, dimethametryn and terbutryn in environmental water samples. Parameters affecting the extraction efficiency such as type and volume of extraction solvent, sample volume, salt type and amount, centrifugation speed and time, and sample $\mathrm{pH}$ were optimized. Under the optimum extraction conditions the method was linear over the range of $10-100$ $\mu \mathrm{g} / \mathrm{L}$ (carbaryl), $8-100 \mu \mathrm{g} / \mathrm{L}$ (atarzine), $7-100 \mu \mathrm{g} / \mathrm{L}$ (propazine) and $9-100$ $\mu \mathrm{g} / \mathrm{L}$ (chlorothalonil, terbutryn and dimethametryn) with correlation coefficients $\left(\mathrm{R}^{2}\right)$ between 0.99 and 0.999 . Limits of detection and quantification ranged from 2.0 to $2.8 \mu \mathrm{g} / \mathrm{L}$ and 6.7 to $9.5 \mu \mathrm{g} / \mathrm{L}$, respectively. The extraction recoveries obtained for ground, lake and river waters were in a range of $75.5 \%$ to $106.6 \%$, with the intra-day and inter-day relative standard deviation lower than $3.4 \%$ for all the target analytes. All of the target analytes were not detected in these samples. Therefore, the proposed SALLE-HPLC-DAD method is simple, rapid, cheap and environmentally friendly for the determination of the aforementioned herbicides, insecticide and fungicide residues in environmental water samples.
\end{abstract}

\section{Keywords}

Environmental Waters, High Performance Liquid Chromatography, Salting-Out Assisted Liquid-Liquid Extraction, Southern Ethiopia, Trace Multiclass Pesticide Residues 


\section{Introduction}

The use of agrochemical is becoming one of the preferred alternatives mainly because of their rapid actions on exterminating disease causing organisms, control insects, weeds and other pests. Extensive and frequent applications of these compounds, pesticides in particular, have greatly improved the quality and quantity of food, and advances in pesticide technology have increased the ability to sustain and improve the health and well-being of the ever growing human population [1]. Unfortunately, these compounds are potential pollutants having deleterious effects on human health, lives of the wild and aquatic animals and that of the inhabitants of the ecosystem in the environment mainly because of the undesirable risks caused from their eco-toxicity, bioaccumulation properties, hormone disrupting effects, etc. [2] [3].

The residues of applied pesticides are usually occurring in the environment at trace/ultra-trace levels [4] [5] [6]. In order to carry out trace enrichment, it is mandatory to search for fairly suitable and reliable sample preparation technique for selective and quantitative extraction of the target pesticide residues from complex sample matrices. To this end, quite a number of solventless and solvent-minimized sample preparation techniques have been developed, validated and applied in the analysis of trace level pesticide contaminants from various water systems and other matrices [7] [8] [9]. However, most of these techniques have their own limitations; for example, passive dosimetry [10] requires longer sample exposure times while membrane assisted solvent extraction (MASE) [11] uses longer extraction times to ensure quantitative analyte enrichment, typically $1 \mathrm{~h}$; a non-selective characteristics of the extraction solvents in dispersive liquidliquid microextraction (DLLME) [12]; limited applications of stir bar sorptive extraction (SBSE), not suiting for strongly polar compounds unless derivatized [13]. On the other hand, the apparatus needed for most of these techniques are expensive and may not easily be available in most laboratories of the developing countries.

Traditional sample preparation techniques such as liquid-liquid extraction (LLE) [14] and solid-phase extraction (SPE) [5] are still popular, methods of choice and used commonly for quantitative extraction of trace multiclass pesticide residues from various environmental waters [15], despite their methodological drawbacks described in scientific literatures [16] [17]. The trace level analytes of interest, occurring in environmental waters and other matrices, are usually enriched in small volume of extracts and subsequently determined utilizing sensitive analytical instruments including HPLC [18], capillary electrophoresis (CE) [19], and Gas chromatography (GC) [20] coupled to different detectors [6]. In a conventional LLE, water immiscible organic solvents are commonly employed for facilitating efficient phase separation between the aqueous solution and non-polar organic solvents; the latter having low dielectric constant [21]. As a result, only non-polar contaminants, e.g., trace pesticide residues, may be extracted and concentrated in the non-polar organic solvents chosen. How- 
ever, LLE procedure can be modified for further extending its applications for enabling efficient extraction of polar pesticide residues from various water samples [22] [23]. This can be achieved by addition of appropriate quantities of a salt to the mixture of the aqueous sample and water-miscible organic solvent, for causing formation of a two-phase system and simultaneous separation of the target analytes into the organic phase [24] [25]. The procedure can also be modified by adding an ion-pair agent, to form extractable ion-pairs, when efficient extraction of high polarity analytes is desired [15] [26]. The salting-out assisted liquid-liquid extraction (SALLE) technique was found to be simple, fast, cheap and environmentally safe and the resulting extracts could directly be introduced or evaporated and then reconstituted into suitable solvent before final instrumental analyses. During the years, merits and application potentials of the SALLE techniques were demonstrated in a number of studies [26], and on this basis this technique was selected as preferred alternative for establishing efficient extraction of pollutant pesticide residues, sampled from the various water samples of this study.

The sampling areas considered in this study, located around the Lake Ziway in Southern Ethiopia, are known for supplying sufficient quantities of agricultural crops including cereals, vegetables and fruits for local and central markets. However, attaining increased productivity, can't be realized without the frequent use of high yield varieties of agrochemicals; herbicides, insecticides, fungicides and fertilizers. This has also been associated with increased importation of pesticides in the recent years, which has raised to, on average, 2400 tons per annum, according the Pesticide Risk Reduction Programme in Ethiopia (PRRP) [27]. Consequently, application of the heavy doses of mixtures of different pesticides, causes accumulation levels the pesticide residues to increase with time [28]; possibly contaminate and pollute the various environmental compartments which enter the food chain and may be causing risk to human health. It was also noted that most of the farmlands are irrigated by pumped water from the Lake Ziway [29].

It was also known that different classes of pesticides including carbaryl, atrazine, propazine, chlorothalonil, dimethametryn and terbutryn were in use at least for the past three decades, and could leach into the water bodies of the surrounding areas. Therefore, the current study has focused on development of a simple, friendly and easy analytical method that enables selective and quantitative extraction of multiclass pesticide residues from different water samples obtained from the surroundings of the Ziway Lake. The technique thus was the SALLE, so as to perform efficient extraction residues of these pesticides from different water samples. Furthermore, experimental parameters influencing performances of the developed technique were optimized and validated. Based on the optimized conditions, the techniques was successfully applied for extraction of the water samples. The reliability of the technique was also evaluated and compared with other similar techniques reported in the literature. 


\section{Materials and Methods}

\subsection{Chemicals and Reagents}

The pesticide standards considered in this study; namely, carbaryl, atrazine, propazine, chlorothalonil, dimethametryn and terbutryn were purchased from Dr. Ehrenstorfer GmbH (Augsburg, Germany). Chemical structure and important physicochemical properties of the standards are provided in Figure 1. Both methanol, purchased from Carlo Erba (Rodano, Italy) and acetonitrile from Sigma Aldrich (Steinheim, Germany) were of HPLC grade solvents and used as mobile phase. Acetone was also purchased from Sigma Aldrich (Steinheim, Germany). All other chemicals, used in this study were of analytical grade reagents. The salts used as salting-out agents including $\mathrm{NaCl}$ and $\mathrm{MgSO}_{4}$ were the products of Sigma Aldrich (Steinheim, Germany) while $\left(\mathrm{NH}_{4}\right)_{2} \mathrm{SO}_{4}$ was from BDH Chemicals Ltd (Poole, England). Hydrochloric acid $(\mathrm{HCl})$ was the product of Sigma-Aldrich (St. Louis, MO, USA). Ultrapure water was obtained by purifying with double distiller, A8000 Aquatron water Still (Bibby Scientific, Staffordshire, UK) and deionizer (EASYPure LF, Dubuque). It was filtered under vacuum through cellulose acetate filter papers $(0.45 \mu \mathrm{m}$, Micro Science) before use. The stock standard solution of $100 \mathrm{mg} / \mathrm{L}$, containing each target analyte, was prepared in methanol. Intermediate standard solution of $10 \mathrm{mg} / \mathrm{L}$ was obtained from the stock solution. Both intermediate solution and other solutions, of lower concentrations, were prepared by diluting with reagent water.

\subsection{Instrumentation}

Chromatographic analyses were performed using Agilent Technologies 1200 series HPLC, equipped with quaternary pump, Agilent 1200 series Vacuum Degasser, Agilent 1200 series Autosampler and Agilent 1200 series diode array de-<smiles>CNC(=O)Oc1cccc2ccccc12</smiles>

Carbaryl<smiles>CCNc1nc(Cl)nc(NC(C)C)n1</smiles>

Atrazine<smiles>CC(C)Nc1nc(Cl)nc(NC(C)C)n1</smiles>

Propazine

$(\log \mathrm{P}=2.36 ; \mathrm{pKa}=10.4)$

$(\log \mathrm{P}=-0.97 ; \mathrm{pKa}=1.7)$

$(\log \mathrm{P}=3.95 ; \mathrm{pKa}=1.7)$<smiles>N#Cc1c(Cl)c(Cl)c(Cl)c(C#N)c1Cl</smiles>

Chlorothalonil<smiles>CCNc1nc(NC(C)C(C)C)nc(SC)n1</smiles>

Dimethametryn<smiles>CCNc1nc(NC(C)(C)C)nc(SC)n1</smiles>

Terbutryn

$(\log \mathrm{P}=2.94 ; \mathrm{pKa}=\mathrm{na}) \quad(\log \mathrm{P}=3.9 ; \mathrm{pKa}=4.0)$

$(\log \mathrm{P}=3.9 ; \mathrm{pKa}=4.3)$

Figure 1. Chemical structures, common names, $\log \mathrm{P}$ (partition coefficient) and $\mathrm{pK}_{\mathrm{a}}$ of the pesticides considered in this study [4] [30]. 
tector (DAD), all purchased from Agilent Technlogies (Agilent Technlogies, Germany). Chromatographic separation of the target compounds was performed on a ZORBAX Eclipse XDB- $\mathrm{C}_{18}$ analytical column $(150 \times 3 \mathrm{~mm}$ i.d., $3.5 \mu \mathrm{m}$ particle size) (Agilent technologies, USA). Data acquisition and processing were accomplished with LC Chemstation software (Agilent Technologies). A pH meter, Adwa, model 1020 (Romania) and centrifuge, Model 800 (China, Beijing) were used during sample preparation.

\subsection{Chromatographic Conditions}

Chromatographic separations were carried out using ternary mobile phase; consisting of reagent water (40\%), acetonitrile (33\%) and methanol (27\%) in isocratic elution mode. The mobile phase flow rate, column temperature, injection volume and monitoring wavelength were $0.9 \mathrm{~mL} / \mathrm{min}, 35^{\circ} \mathrm{C}, 10 \mu \mathrm{L}$ and $230 \mathrm{~nm}$ respectively. Peak area was utilized as an instrumental response. Quantitative determination of the instrumental responses was based on the peak areas. Under this chromatographic condition, a good baseline separation was obtained for all the target analytes.

\subsection{Sampling Sites and Sample Pretreatment}

The representative environmental water samples were collected from different localities in the surrounding of Ziway town. Lake water samples were collected from Ziway Lake, ground water samples were from bore holes around Abine Garmama in the Ziway town and river waters from Buchesa River (outflow river from Ziway Lake). Geographical locations of the sampling sites are as follows: Lake Ziway is located at latitude of $8^{\circ} 00^{\prime} 21.94^{\prime \prime} \mathrm{N}$ and longitude $38^{\circ} 50^{\prime} 31.78^{\prime \prime} \mathrm{E}$ with elevation $1637.7 \mathrm{~m}$ above sea level. Ziway town is also located at latitude of $7^{\circ} 55^{\prime} 43.38^{\prime \prime} \mathrm{N}$ and longitude $38^{\circ} 43^{\prime} 15.99^{\prime \prime} \mathrm{E}$ with elevation $1648.7 \mathrm{~m}$ above sea level. All water samples were obtained in brown amber bottles and carried to the Analytical Laboratory of the Chemistry Department, Addis Ababa University, within $24 \mathrm{~h}$. Each sample was then filtered through $0.45-\mu \mathrm{m}$ membrane filter, before use, and then stored in a brown glass bottle, in a refrigerator at $4^{\circ} \mathrm{C}$, for a maximum of $24 \mathrm{~h}$ [31]. The $\mathrm{pH}$ of each water sample was adjusted to the required value utilizing diluted solutions of $\mathrm{HCl}$ and $\mathrm{NaOH}$.

\subsection{Experimental Procedure for the SALLE}

The sample solution of $5 \mathrm{~mL}$ was first spiked with predetermined volume of the standard solution containing mixture of the target analytes and quantitatively transferred to each of the $15 \mathrm{~mL}$ screw capped polyethylene test tubes. Then, 1.5 $\mathrm{mL}$ acetonitrile and $1.4 \mathrm{~g} \mathrm{NaCl}$ were added. Thereafter, the solution was shaken gently for $1 \mathrm{~min}$, to ensure complete dissolution of the salt. This was followed by centrifugation of the solution at $4000 \mathrm{rpm}$ for $6 \mathrm{~min}$, which resulted in phase separation. Then, the upper organic phase, was carefully withdrawn using $1 \mathrm{~mL}$ micro-syringe and quantitatively transferred to a vial, for subsequent injection to the HPLC system. 


\section{Results and Discussion}

\subsection{Optimization of the SALLE Procedure}

In this study, vital parameters influencing the extraction and analyte separation were optimized in order to obtain maximum extraction efficiency and sensitivity [32] [33]. Experimental parameters studied and optimized include the type and volume of extraction solvent, sample volume and $\mathrm{pH}$ of the aqueous samples, type and concentration of the salt and centrifugation time and speed.

\subsubsection{Selection of the Organic Solvent}

One of the critical parameters influencing the SALLE procedure is selection of appropriate extraction solvent. The organic solvent used for extraction in this technique should be highly polar, miscible in water in all proportions and induce phase separation upon addition of appropriate salt [23] [34]. In this study, extraction performances of the following solvents for trace multiclass pesticides were evaluated based on the polarity index given in parenthesis: acetonitrile (5.8), acetone (5.1) and methanol (5.1) [25]. Accordingly, series of experiments were performed using $5 \mathrm{~mL}$ water sample spiked at $50 \mu \mathrm{g} / \mathrm{L}$ level of the mixture containing the target analytes. It was observed that when acetonitrile was used as extraction solvent, the aqueous and organic phases were adequately separated while the other two solvents failed to cause the required phase separation. Use of acetonitrile, as the preferred extraction solvent in SALLE, for efficient isolation of polar organic compounds was reported in the literature [35]. In addition, acetonitrile is compatible with various types of instruments such as GC, HPLC, CE, inductively coupled plasma and AAS [25]. Furthermore, acetonitrile is less harmful than other organic solvents that are commonly used in conventional LLE as well as other LPME techniques and thus it is more favorable with a green chemistry context. Thus, acetonitrile was selected and used throughout this study.

\subsubsection{Effect of the Extraction Solvent Volume}

The extraction solvent volume also plays significant role on the extraction efficiency of the SALLE procedure. Generally, the optimum extraction solvent volume should offer high extraction efficiency as well as sufficient volume of the organic phase for the subsequent analysis [33]. The volume of acetonitrile, as extraction solvent, was varied over the range of $0.5-2.5 \mathrm{~mL}$. With lower volumes of acetonitrile, i.e., 0.5 and $1 \mathrm{~mL}$, phase separation between the aqueous and organic phases was found to be insufficient. The peak areas of the target analytes decreased when volume of acetonitrile is greater than $1.5 \mathrm{~mL}$ which may be attributed to dilution of the organic phase, Figure 2(a). The highest instrumental responses were obtained with $1.5 \mathrm{~mL}$ of acetonitrile and thus used as optimum extraction solvent volume.

\subsubsection{Effect of Sample Volume}

The study of the sample volume is the other important parameter that must be considered in order to establish standard experimental conditions. Accordingly, 


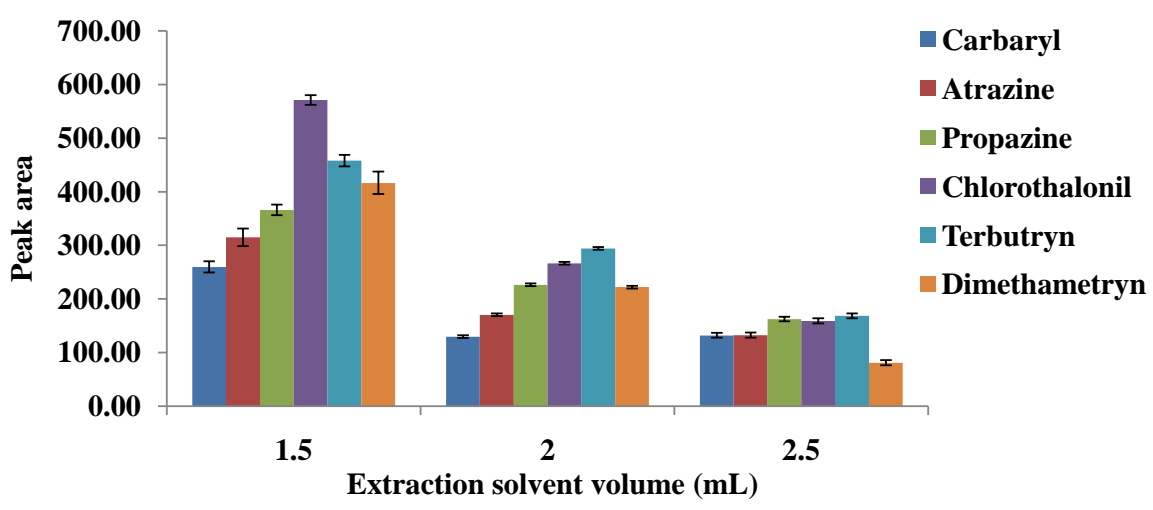

(a)

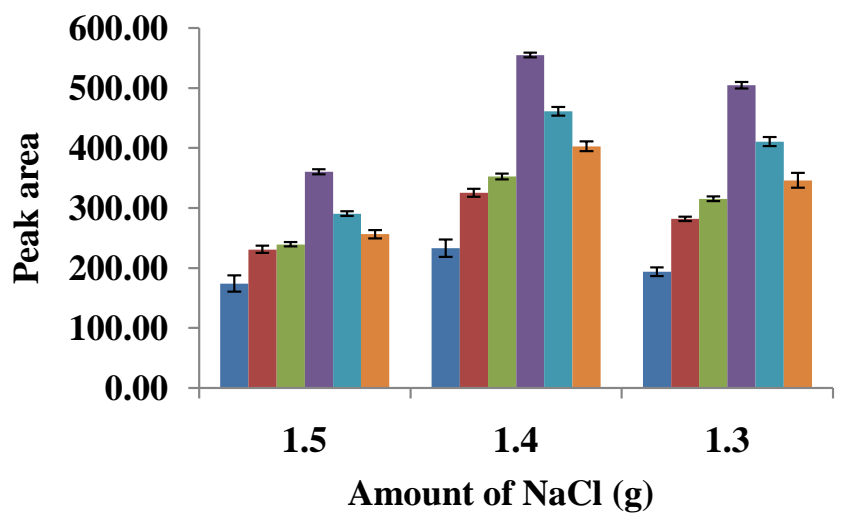

n Carbaryl

Atrazine

- Propazine

- Chlorothalonil

- Terbutryn

Dimethametryn

(b)

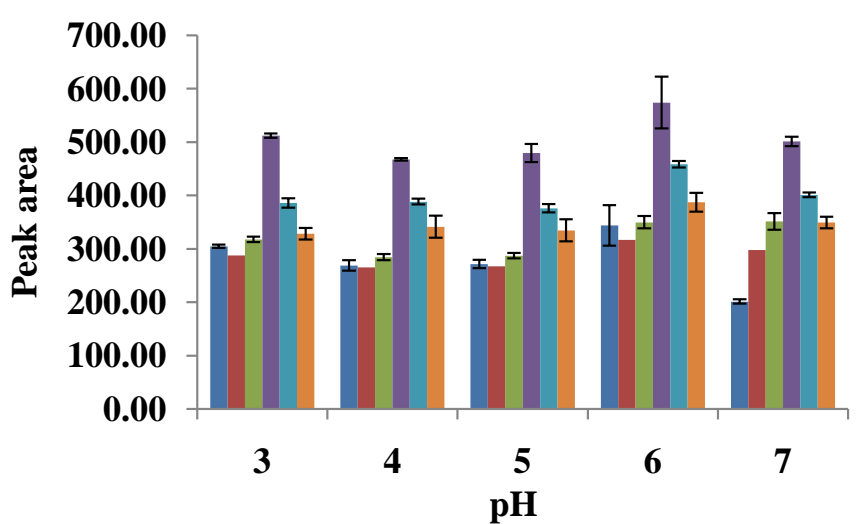

Carbaryl

Atrazine

Propazine

Chlorothalonil

Terbutryn

Dimethametryn

(c)

Figure 2. (a) Effect of the extraction solvent volume; (b) effect of the amount of $\mathrm{NaCl}$ and (c) effect of $\mathrm{pH}$ on the SALLE efficiency. Extraction conditions (a): sample size, $5 \mathrm{~mL}$ spiked at $50 \mu \mathrm{g} / \mathrm{L}$; amount of salt added, $1.5 \mathrm{~g} \mathrm{NaCl}$; shaking time, $1 \mathrm{~min}$; centrifugation speed, $3500 \mathrm{rpm}$; centrifugation time, $3 \mathrm{~min} ; \mathrm{pH}=7.0, \mathrm{n}=3$, (b): volume of acetonitrile, $1.5 \mathrm{~mL}$ and other parameters are the same as in (a), (c): amount of salt added, $1.4 \mathrm{~g} \mathrm{NaCl}$; centrifugation speed, $4000 \mathrm{rpm}$; centrifugation time, $6 \mathrm{~min}$ and other parameters are the same as in (b).

volume of the reagent water was varied from 3 to $7 \mathrm{~mL}$, to study the effect of sample volume on SALLE. At lower sample volume, phase separation was not observed, may be due to insufficient volume ratio of the sample to that of organic solvent. On the other hand, with increase in the sample volume, beyond $3 \mathrm{~mL}$, 
the peak areas of all the target analytes showed increasing tendencies. However, above $5 \mathrm{~mL}$ of the sample volume, the instrumental responses showed decreasing extraction tendencies which may be caused by the dilution effect caused by increased sample volume. Similar observations were also noted by other workers [23]. Therefore, $5 \mathrm{~mL}$ sample volume was selected as optimum and used for the subsequent experimental works.

\subsubsection{Effect of the Salt Type and Amount}

The addition of a salt into the sample solution cause increase in ionic strength of the sample solution and facilitates the transfer of target analytes from the aqueous phase to the organic solvent phase [36] [37]. In order to evaluate this effect, $1.5 \mathrm{~g}$ of each of the salts; viz., sodium chloride $(\mathrm{NaCl})$, magnesium sulphate $\left(\mathrm{MgSO}_{4}\right)$ and ammonium sulphate $\left(\left(\mathrm{NH}_{4}\right)_{2} \mathrm{SO}_{4}\right)$, were added as potential salting-out agents. The results obtained revealed that $\mathrm{NaCl}$ is a suitable salting-out agent and used for further experiments.

The amount of $\mathrm{NaCl}$ was also varied from 1 to $1.7 \mathrm{~g}$, at five points. It was observed that when smaller amounts, i.e., $1 \mathrm{~g}$ and $1.2 \mathrm{~g}$ salt were added, phase separation was not observed. On the other hand, with larger amounts of $\mathrm{NaCl}, 1.6$ and $1.7 \mathrm{~g}$, dissolution of the salts added was not complete [36]. Addition of $1.4 \mathrm{~g} \mathrm{NaCl}$ provided the well resolved chromatogram and the highest peak areas, Figure 2(b), for all the analytes and thus chosen as the optimum quantity of the salt.

\subsubsection{Effect of Centrifugation Speed and Time}

Centrifugation of the sample solution obviously influences kinetics of the extraction and enhances contact between the organic solvent and aqueous solution and thus facilitates formation of the two-phase system in the SALLE technique [34]. In this study, the effect of centrifugation speed was varied in the range of 2000 to $4000 \mathrm{rpm}$, with interval of $500 \mathrm{rpm}$ while the centrifugation time is kept at 5 min. It was found that the peak area of all target analyte increases with increasing centrifugation speed. However, centrifugations speed of higher than 4000 rpm were not conducted due to the instrumental limitations. As a result, 4000 rpm was utilized as optimum centrifugation speed for further experiments.

Optimizing the time required for phase separation is also important analytical step, in order to obtain a clear extract [33]. To this end, time of centrifugation was varied from 4 to $8 \mathrm{~min}$, at five points, within $1 \mathrm{~min}$ interval, keeping the centrifugation speed at the optimum of $4000 \mathrm{rpm}$. The experimental results revealed that centrifugation time of $6 \mathrm{~min}$ to be the optimum and used throughout this study.

\subsubsection{Effect of the Sample $\mathrm{pH}$}

In this study, the effect of $\mathrm{pH}$ of sample solution was studied over the range of 3 to 7. Based on the experimental results showed that, the peak areas of all the target analytes increased with rise in the sample solution $\mathrm{pH}$, up to $\mathrm{pH}$ 6. This may be due to the enhanced stability of the pesticide compounds, both in weakly acidic and alkaline environments [38]. However, beyond $\mathrm{pH}$ 6, the peak areas 
started to decrease mainly because of degradation or ionization of the analytes in strongly alkaline conditions [4], Figure 2(c). Therefore, sample solution of $\mathrm{pH} 6$ was selected for subsequent experiments.

\subsection{Evaluation of the Proposed Method}

\subsubsection{Calibration Curves and Analytical Performance Characteristics}

The proposed SALLE technique coupled to the HPLC-DAD detection was evaluated at different concentration levels of the standard solution ranging from 7 $\mu \mathrm{g} / \mathrm{L}$ to $100 \mu \mathrm{g} / \mathrm{L}$. Utilizing the optimized parameters, each concentration level was extracted and injected in triplicate. Then, the calibration curves were constructed by plotting the peak areas as instrumental responses versus the target pesticide concentrations. The correlation coefficient $\left(R^{2}\right)$ of the calibration curves were 0.990 or better, for all the analytes considered, confirming good linearity over the studied concentration range. The limits of detection (LOD) and quantification (LOQ), defined as the minimum analyte concentrations yielding 3 and 10 times the signal-to-noise ratio $(\mathrm{S} / \mathrm{N})$, were in the range of $2.0-2.8 \mu \mathrm{g} / \mathrm{L}$ and $6.7-9.5 \mu \mathrm{g} / \mathrm{L}$, respectively. The figures of merit of the proposed technique are given in Table 1.

\subsubsection{Precision Study}

Evaluation of the precision of the proposed method was based on the results obtained from intra-day (repeatability) and inter-day (reproducibility) studies applying the optimized conditions. This was performed by extracting the water samples which were spiked with the standard solution, at concentration level of $25 \mu \mathrm{g} / \mathrm{L}$, for both studies. For intra-day precision, the spiked concentration was extracted and injected in triplicate on the same day, under the same experimental conditions. Similarly, inter-day precision of the method was also assayed during three consecutive days, at the same concentration level with that spiked for intra-day study. The results of both the intra- and inter-day precisions, expressed as relative standard deviations (\%RSD) of the peak areas, are shown in Table 1. The results of the precision studies for the proposed SALLE technique have demonstrated acceptable precision [39], and thus can reliably be utilized

Table 1. Statistical and performance characteristics and precision of the proposed SALLE technique

\begin{tabular}{cccccccc}
\hline Analyte & $\begin{array}{c}\text { Linear } \\
\text { range } \\
(\mu \mathrm{g} / \mathrm{L})\end{array}$ & $\mathrm{R}^{2}$ & $\begin{array}{c}\mathrm{LOD} \\
(\mu \mathrm{g} / \mathrm{L})\end{array}$ & $\begin{array}{c}\mathrm{LOQ} \\
(\mu \mathrm{g} / \mathrm{L})\end{array}$ & $\begin{array}{c}\text { Regression } \\
\text { equation }\end{array}$ & $\begin{array}{c}\text { Intra-day } \\
(\% \mathrm{RS})\end{array}$ & $\begin{array}{c}\text { Inter-day } \\
(\% \mathrm{RSD})\end{array}$ \\
\hline Carbaryl & $10-100$ & 0.991 & 2.8 & 9.5 & $\mathrm{Y}=8.24 \mathrm{x}+23.05$ & 3.37 & 3.15 \\
Atrazine & $8-100$ & 0.992 & 2.3 & 7.7 & $\mathrm{Y}=8.99 \mathrm{x}+34.31$ & 1.55 & 2.41 \\
Propazine & $7-100$ & 0.995 & 2.0 & 6.7 & $\mathrm{Y}=10.00 \mathrm{x}+28.94$ & 2.45 & 1.97 \\
Chlorothalonil & $9-100$ & 0.991 & 2.7 & 8.9 & $\mathrm{Y}=16.44 \mathrm{x}+41.85$ & 1.44 & 1.7 \\
Terbutryn & $9-100$ & 0.990 & 2.3 & 8.3 & $\mathrm{Y}=13.12 \mathrm{x}+24.59$ & 1.69 & 3.03 \\
Dimethametryn & $9-100$ & 0.999 & 2.6 & 8.5 & $\mathrm{Y}=11.47 \mathrm{x}+26.92$ & 2.15 & 1.38 \\
\hline
\end{tabular}


for monitoring of the target analytes in different water samples that could be obtained from varied sources and localities.

\subsubsection{Application of the Developed Method to the Real Samples}

The applicability of the proposed method was evaluated by extracting all the three water samples; river, ground and lake water samples following the optimized SALLE analytical technique. The results obtained revealed that there were no target analytes detected in any one of the water samples analyzed. This could be either the water samples analyzed were free from the residues of target pesticides or contained concentrations below the detection limits. Consequently, the applicability of the technique was further investigated by extracting the three water samples spiked at concentration level of $50 \mu \mathrm{g} / \mathrm{L}$, the peak areas of which compared with those obtained from the spiked reagent water at the same concentration levels, in order to assess the matrix effects. The relative recovery (\%RR), defined as the ratios of the peak areas of spiked real water extracts to the peak areas of spiked reagent water extracts [40] was used to evaluate the matrix effect. The calculated \%RR and \% RSD obtained for the extracts of both real water samples and reagent water were in the acceptable ranges [39], Table 2. Typical chromatograms for water samples from Ziway Lake, before and after spiking with $50 \mu \mathrm{g} / \mathrm{L}$ using the optimized SALLE technique are provided in Figure 3.

\subsubsection{Comparison with Other Reported Methods}

The extraction efficiency of the proposed SALLE procedure has been compared with similar analytical techniques reported in the scientific literatures. On the basis of the parameters indicated in Table 3, it was noted that the technique de-

Table 2. \%RR and \%RSD of the environmental water samples $(n=3)$, analyzed for residues of the target analytes by SALLE technique.

\begin{tabular}{cccccccc}
\hline \multirow{2}{*}{ Pesticides } & \multirow{2}{*}{$\begin{array}{c}\text { Spiked level, } \\
\mu \mathrm{g} / \mathrm{L}\end{array}$} & \multicolumn{2}{c}{ Lake water } & \multicolumn{2}{c}{ Ground water } & \multicolumn{2}{c}{ River water } \\
\cline { 3 - 8 } Carbaryl & 0 & \%RR & \%RSD & \%RR & $\%$ RSD & \%RR & $\%$ RSD \\
\hline \multirow{2}{*}{ Atrazine } & 50 & 106.6 & 7.8 & 92.7 & 6.4 & 89.1 & 2.3 \\
& 0 & nd & - & nd & - & nd & - \\
Propazine & 50 & 98.1 & 3 & 92.5 & 2.9 & 86.8 & 1.6 \\
& 0 & nd & - & nd & - & nd & - \\
Chlorothalonil & 50 & 96.5 & 1.6 & 93.6 & 0.8 & 85.7 & 2 \\
& 0 & nd & - & nd & - & nd & - \\
Terbutryn & 50 & 75.5 & 6.4 & 87.1 & 1.5 & 86.9 & 10.1 \\
& 0 & nd & - & nd & - & nd & - \\
& 50 & 99.8 & 4.6 & 85.2 & 3.8 & 83.3 & 1.6 \\
Dimethametryn & 0 & nd & - & nd & - & nd & - \\
& 50 & 98.9 & 1 & 83.4 & 5.9 & 83.8 & 4.9 \\
\hline
\end{tabular}

nd $=$ not detected. 


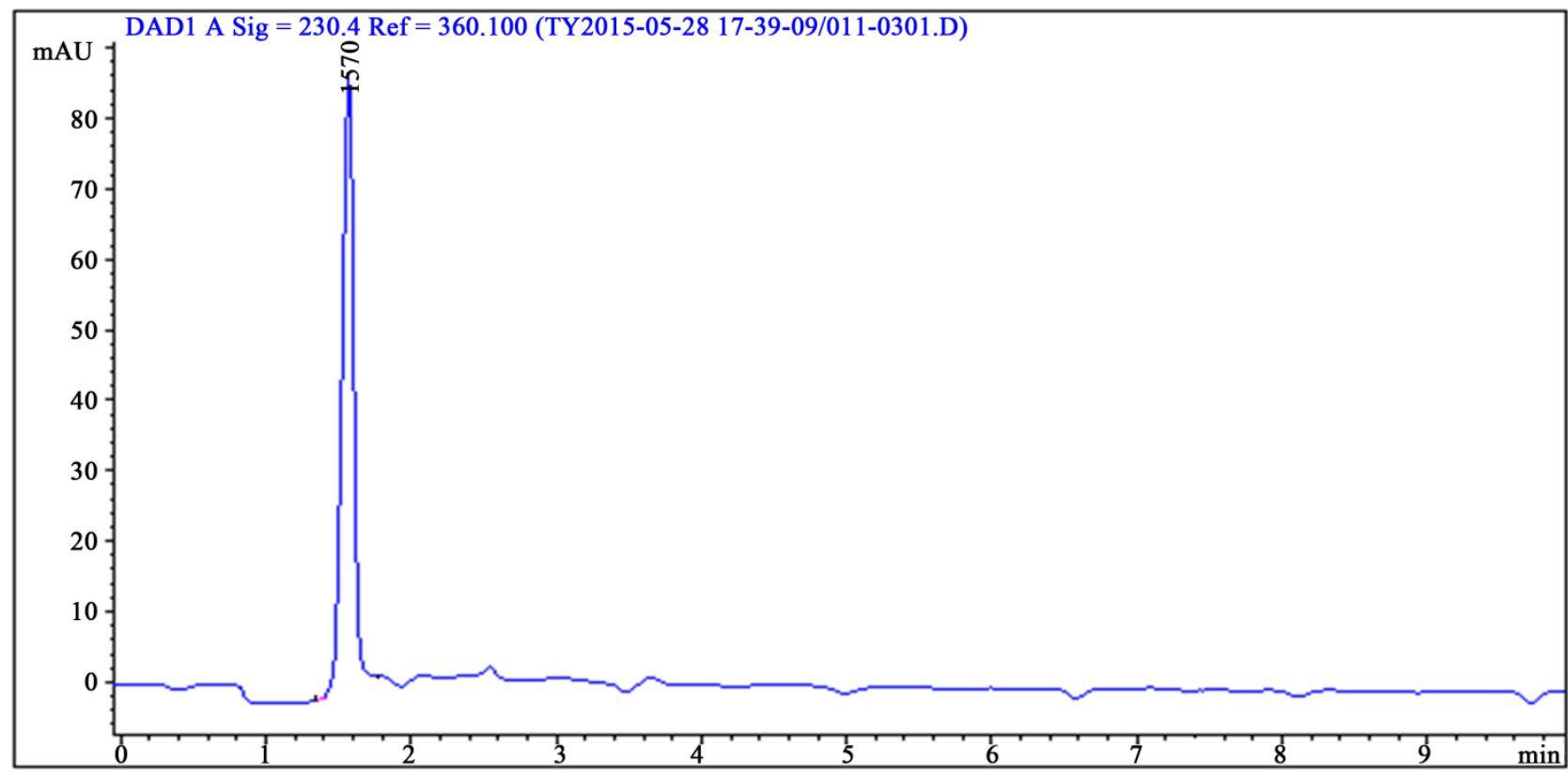

(a)

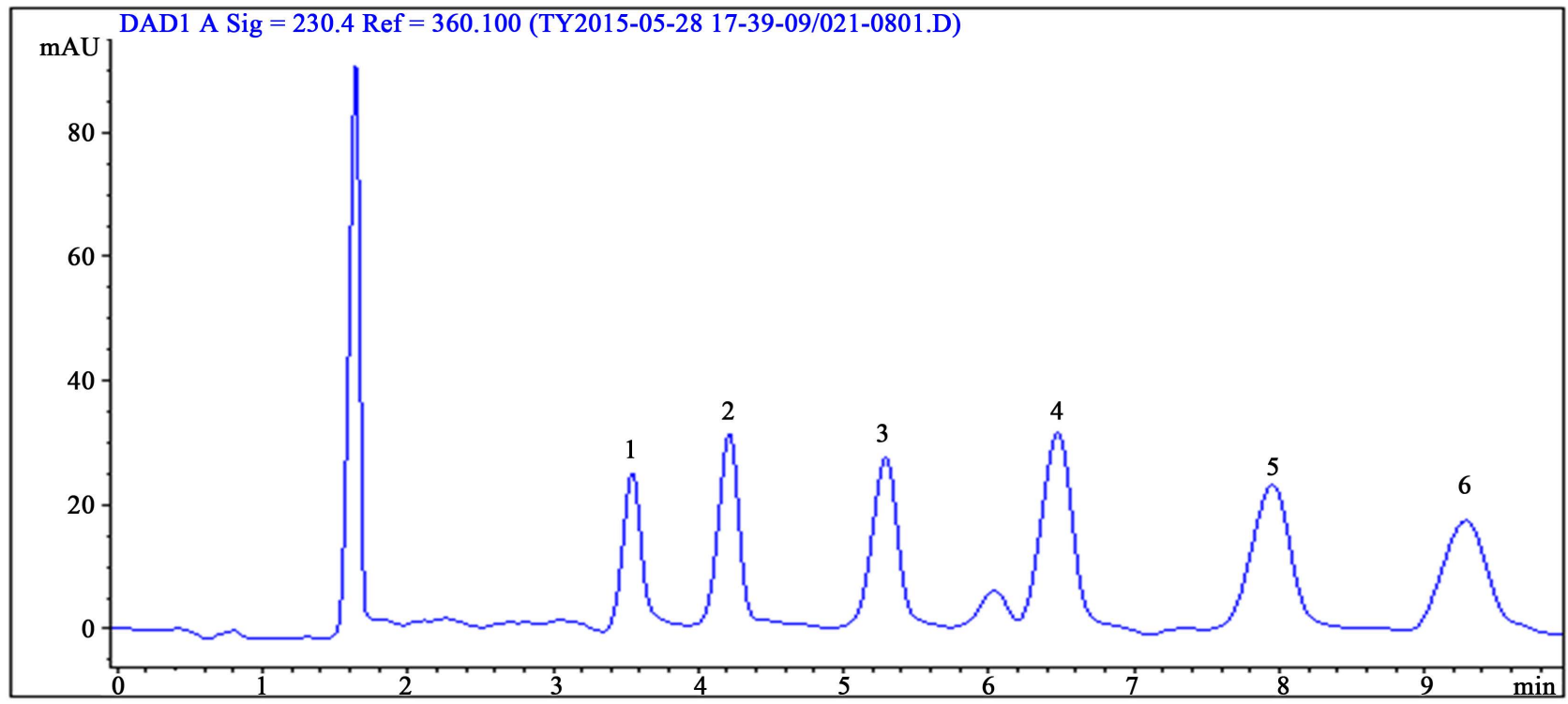

(b)

Figure 3. Typical representative chromatograms for water samples from blank (a) and spiked (b) Ziway Lake. Extraction conditions: $5 \mathrm{~mL}$ spiked at $50 \mu \mathrm{g} / \mathrm{L}$; volume of acetonitrile, $1.5 \mathrm{~mL}$; amount of salt added, $1.4 \mathrm{~g} \mathrm{NaCl}$; shaking time, $1 \mathrm{~min}$; centrifugation speed, $4000 \mathrm{rpm}$; centrifugation time, $6 \mathrm{~min} ; \mathrm{n}$ =3. Peaks: 1, Carbaryl; 2, Atrazine; 3, Propazine; 4, Chlorothalonil; 5, Terbutryn; 6, Dimethametryn.

veloped in this study was found to use shorter extraction time and smaller or comparable sample volume than the other methods. Moreover, the technique utilizes classical laboratory equipments as well as less toxic organic solvent (acetonitrile), which can be found in common research laboratories, e.g., in the developing countries. It also offered similar or better LODs and comparable linearity ranges with others cited for comparison. Based on the experimental findings the proposed technique can be considered as one of the preferred alternative, 
Table 3. Comparison of the proposed SALLE method with related reported techniques.

\begin{tabular}{|c|c|c|c|c|c|c|c|}
\hline Analytical methods & Analyte studied & $\begin{array}{l}\text { Sample type and } \\
\text { its volume }(\mathrm{mL})\end{array}$ & $\mathrm{LDR}(\mu \mathrm{g} / \mathrm{L})$ & LODs $(\mu \mathrm{g} / \mathrm{L})$ & $\%$ RDS & $\begin{array}{l}\text { Extraction } \\
\text { time }(\min )\end{array}$ & Ref. \\
\hline $\begin{array}{l}\text { SALLE-capillary } \\
\text { LC-DAD }\end{array}$ & $\begin{array}{l}\text { Cephoperazone, cefquinome, } \\
\text { cephalexin, cephapirin, } \\
\text { cephaloniun, cephamandole, } \\
\text { cephazolin and cephadroxile }\end{array}$ & Water (4) & $1.3-100$ & $0.4-1.3$ & $0.6-9.9$ & $<10$ & [26] \\
\hline $\begin{array}{l}\text { SALLE-capillary } \\
\text { LC-DAD }\end{array}$ & $\begin{array}{l}\text { Cephoperazone, cefquinome, } \\
\text { cephalexin, cephapirin, } \\
\text { cephaloniun, cephamandole, } \\
\text { cephazolin and cephadroxile }\end{array}$ & Banana juice (2.5) & $10-500$ & $3-13$ & $1.2-9.9$ & $<10$ & [26] \\
\hline CPE-HPLC-DAD & $\begin{array}{l}\text { Thiamethoxam, imidacloprid, } \\
\text { acetamiprid, thiacloprid }\end{array}$ & Water (18) & $4-2000$ & $0.8-1.2$ & - & 17 & [41] \\
\hline $\begin{array}{l}\text { IL-MNPs based } \\
\text { SPE-capillary } \\
\text { LC-DAD }\end{array}$ & $\begin{array}{l}\text { Thifensulfuron methyl, } \\
\text { metsulfuron methyl, } \\
\text { triasulfuron, tribenuron methyl } \\
\text { and primisulfuron methyl }\end{array}$ & Water (50) & $5-100$ & $5-100$ & $2.3-4.9$ & - & {$[42]$} \\
\hline $\begin{array}{l}\text { Au-TEOS based } \\
\text { SPE-capillary } \\
\text { LC-DAD }\end{array}$ & $\begin{array}{l}\text { Bensulfuron-methyl, } \\
\text { metsulfuron-methyl, } \\
\text { pyrazosulfuron-methyl, } \\
\text { thifensulfuron-methyl } \\
\text { and triasulfuron }\end{array}$ & Water (10) & $50-1000$ & $2-9$ & $2.1-4.5$ & - & [43] \\
\hline $\begin{array}{c}\text { Au-NP-IL-silica } \\
\text { based SPE-capillary } \\
\text { LC-DAD }\end{array}$ & $\begin{array}{l}\text { Bensulfuron-methyl, } \\
\text { metsulfuron-methyl, } \\
\text { pyrazosulfuron-methyl, } \\
\text { thifensulfuron-methyl } \\
\text { and triasulfuron }\end{array}$ & Water (10) & $50-1000$ & $2-6$ & $2.8-4$ & - & [43] \\
\hline SPE-CE-UV & $\begin{array}{l}\text { Triasulfuron, rimsulfuron, } \\
\text { flazasul-furon, } \\
\text { metsulfuron-methyl } \\
\text { and chlorsulfuron }\end{array}$ & $\begin{array}{l}\text { Aqueous extract } \\
\text { of grapes (250) }\end{array}$ & $\begin{array}{c}0.97-200 \\
(\mu \mathrm{g} / \mathrm{kg})\end{array}$ & $\begin{array}{c}0.97-8.3 \\
(\mu \mathrm{g} / \mathrm{kg})\end{array}$ & $5.2-21.4$ & $>120$ & [44] \\
\hline SPE-HPLC-MS & $\begin{array}{l}\text { Amidosulfuron, Aimsulfuron, } \\
\text { Nicosulfuron, Thifensulfuron } \\
\text { Methyl, Tribenuron Methyl } \\
\text { and Azoxystrobin }\end{array}$ & Water (1000) & $15-150$ & $5-8.1$ & - & $>60$ & [45] \\
\hline \multirow{3}{*}{ SALLE-HPLC-DAD } & Carbaryl, atrazine, propazine, & Lake water (5) & & & $1-7.8$ & & \multirow{3}{*}{$\begin{array}{l}\text { Current } \\
\text { study }\end{array}$} \\
\hline & $\begin{array}{l}\text { chlorothalonil, } \\
\text { dimethametryn and terbutryn }\end{array}$ & River water (5) & $7-100$ & $2-2.8$ & $1.6-10$ & $<8$ & \\
\hline & & Ground water (5) & & & $0.67-6.42$ & & \\
\hline
\end{tabular}

having promising future for selective and quantitative extraction of trace level pesticide pollutants considered in this study and others having polar chemical natures and/or ionizable pollutants contaminating various environmental water systems.

\section{Conclusion}

The analytical technique, SALLE combined with HPLC-DAD, was developed for the analysis of fungicide, herbicides and insecticide in environmental waters. The consumption of the extraction solvent (acetonitrile) was reduced to a very 
low level compared to convectional extraction procedures while ensuring operational convenience as well as benign extraction/cleanup performance. It provides a green, fast, economical and simple method for the analysis of multiclass pesticides residue in water sample matrices. Under the optimum extraction condition the method has large linear range with correlation coefficients $\left(\mathrm{R}^{2}\right)$ between 0.99 and 0.999 , low limits of detection and quantification, and satisfactory extraction recoveries for ground, lake and river water. Therefore, the developed method is a powerful tool for quality control of multiclass pesticides residue in environmental water samples.

\section{Acknowledgements}

The Departments of Chemistry of Addis Ababa University is greatly acknowledged for providing all the necessary laboratory facilities and resources required for performing the experimental works. All the pesticide standards and consumables were from “Trace Level Pollutant Analyses, ETH:04" project, supported by the International Science Program (ISP). Fruitful scientific discussions held with the senior doctoral fellows of the Environmental Analytical Chemistry research group, during the years, are highly appreciated. Doctoral studies of Yosef Alemayehu was sponsored by Debre Berhan University.

\section{References}

[1] Megersa, N. (2015) Hollow Fiber-Liquid Phase Microextraction for Trace Enrichment of the Residues of Atrazine and its Major Degradation Products from Environmental Water and Human Urine Samples. Analytical Methods, 7, 9940-9948. https://doi.org/10.1039/C5AY01927C

[2] Merdassa, Y., Liu, J. and Megersa, N. (2013) Development of a One-Step Microwave Assisted Extraction Method for Simultaneous Determination of Organophosphorus Pesticides and Fungicides in Soils by Gas Chromatography-Mass Spectrometry. Talanta, 114, 227-234. https://doi.org/10.1016/j.talanta.2013.04.035

[3] Westbom, R., Hussen, A., Megersa, N., Retta, N., Mathiasson, L. and Björklund, E. (2008) Assessment of Organochlorine Pesticide Pollution in Upper Awash Ethiopian State Farm Soils using Selective Pressurised Liquid Extraction. Chemosphere, 72, 1181-1187. https://doi.org/10.1016/j.chemosphere.2008.03.041

[4] Megersa, N. and Jonsson, J.A. (1998) Trace Enrichment and Sample Preparation of Alkylthio-s-Triazine Herbicides in Environmental Waters Using a Supported Liquid Membrane Technique in Combination with High-Performance Liquid Chromatography. Analyst, 125, 225-231. https://doi.org/10.1039/a705361d

[5] Sabik, H., Jeannot, R. and Rondeau, B. (2000) Multiresidue Methods Using Solid Phase Extraction Techniques for Monitoring Priority Pesticides, including Triazines and Degradation Products, in Ground and Surface Waters. Journal of Chromatography A, 885, 217-236. https://doi.org/10.1016/S0021-9673(99)01084-5

[6] Gaetano, Y.D., Hubert, J. Mohamadou, A., Boudesocque, S., Plantier-Royon, R., Renault, J. and Dupont, L. (2016) Removal of Pesticides from Wastewater by Ion Pair Centrifugal Partition Extraction Using Betaine-Derived Ionic Liquids as Extractants. Chemical Engineering Journal, 285, 596-604. https://doi.org/10.1016/j.cej.2015.10.012

[7] Gure, A., Lara, F.J., Megersa, N., Garcia-Campana, A.M. and Olmo-Iruela, M.D. 
(2013) Hollow Fiber Liquid Phase Microextraction Combined with Capillary HPLC for the Selective Determination of Six Sulfonylurea Herbicides in Environmental Water. Journal of Separation Science, 36, 3395-3401.

https://doi.org/10.1002/jssc.201300652

[8] Tankiewicz, M., Fenik, J. and Biziuk, M. (2011) Solventless and Solvent Minimized Sample Preparation Techniques for Determining Currently used Pesticides in Water Samples. Talanta, 86, 8-22. https://doi.org/10.1016/j.talanta.2011.08.056

[9] Tankiewicz, M., Fenik, J. and Biziuk, M. (2010) Determination of Organophosphorus and Organonitrogen Pesticides in Water Samples. Trends in Analytical Chemistry, 29, 1050-1063. https://doi.org/10.1016/j.trac.2010.05.008

[10] Kot-Wasik, A., Zabiegała, B., Urbanowicz, M., Dominiak, E., Wasik, A. and Namiesnik, J. (2007) Advances in Passive Sampling in Environmental Studies. Analytical Chimica Acta, 602, 141-163. https://doi.org/10.1016/j.aca.2007.09.013

[11] Hauser, B., Schellin, M. and Popp, P. (2004) Membrane Assisted Solvent Extraction of Triazines, Organochlorine and Organophosphorus Compounds in Complex Samples Combined with Large Volume Injection Gas Chromatography/Mass Spectrometric Detection. Analytical Chemistry, 76, 6029-6038.

https://doi.org/10.1021/ac0492923

[12] Zhao, R.S., Diao, C.P., Chen, Q.F. and Wang, X. (2009) Sensitive Determination of Amide Herbicides in Environmental Water Samples by a Combination of Solid Phase Extraction and Dispersive Liquid-Liquid Microextraction Prior to GC-MS. Journal of Separation Science, 32, 1069-1074. https://doi.org/10.1002/jssc.200800677

[13] Bicchi, C., Cordero, C., Liberto, E., Rubiolo, P., Sgorbini, B., David, F. and Sandra, P. (2005) Dual-Phase Twisters: A New Approach to Headspace Sorptive Extraction and Stir Bar Sorptive Extraction. Journal of Chromatography A, 1094, 9-16.

[14] Lambropoulou, D.A. and Albanis, T.A. (2007) Liquid Phase Microextraction Techniques in Pesticide Residue Analysis. Journal of Biochemical and Biophysical Methods, 70, 195-228.

[15] Gure, A., Megersa, N. and Retta, N. (2014) Ion-Pair Assisted Liquid-Liquid Extraction for Selective Separation and Analysis of Multiclass Pesticide Residues in Environmental Waters. Analytical Methods, 6, 4633-4642. https://doi.org/10.1039/C4AY00285G

[16] Rezaee, M., Yamini, Y. and Faraji, M. (2010) Evolution of Dispersive Liquid-Liquid Microextraction Method. Journal of Chromatography A, 1217, 2342-2357.

[17] Bedassa, T., Gure, A. and Megersa, N. (2015) Low Density Solvent Based Dispersive Liquid-Liquid Microextraction and Preconcentration of Multiresidue Pesticides in Environmental Waters for Liquid Chromatographic Analysis. Analytical Chemistry, 70, 1199-1206. https://doi.org/10.1134/S1061934815100184

[18] Tsochatzis, E.D., Tzimou-Tsitouridal, R., Menkissoglu-Spiroudi, U., Karpouzas, D.G. and Papageorgiou, M. (2012) Development and Validation of an HPLC-DAD Method for the Simultaneous Determination of most Common Rice Pesticides in Paddy Water Systems. International Journal of Environmental Analytical Chemistry, 92, 548-560. https://doi.org/10.1080/03067310903229943

[19] Chicharro, M., Bermejo, E., Sanchez, A., Zapardiel, A., Fernandez-Gutierrez, A. and Arraez, D. (2005) Multiresidue Analysis of Phenylurea Herbicides in Environmental Waters by Capillary Electrophoresis using Electrochemical Detection. Analytical and Bioanalytical Chemistry, 382, 519-526. https://doi.org/10.1007/s00216-004-2840-6

[20] Zhang, Z., Lefebvre, T., Kerr, C. and Osprey, M. (2014) Simultaneous Extraction 
and Determination of Various Pesticides in Environmental Waters. Journal of Separation Science, 37, 3699-3705. https://doi.org/10.1002/jssc.201400855

[21] Teju, E., Tadesse, B. and Megersa, N. (2017) Salting-Out-Assisted Liquid-Liquid Extraction for the Preconcentration and Quantitative Determination of Eight Herbicide Residues Simultaneously in Different Water Samples with High-Performance Liquid Chromatography. Separation Science and Technology, 1-11. https://doi.org/10.1080/01496395.2016.1276596

[22] Nanita, S.C. and Padivitage, N.L.T. (2013) Ammonium Chloride Salting-Out Extraction/Cleanup for Trace Level Quantitative Analysis in Food and Biological Matrices by Flow Injection Tandem Mass Spectrometry. Analytical Chimica Acta, 768, $1-11$.

[23] Gure, A., Lara, F.J., Moreno-Gonzalez, D., Megersa, N., Olmo-Iruela, M. and Garcia-Campana, A.M. (2014) Salting-Out Assisted Liquid-Liquid Extraction Combined with Capillary HPLC for the Determination of Sulfonylurea Herbicides in Environmental Water and Banana Juice Samples. Talanta, 127, 51-58.

[24] Noche, G.G., Laespada, M.E.F., Pavón, J.L.P., Cordero, B.M. and Lorenzo, S.M. (2011) In Situ Aqueous Derivatization and Determination of Non-Steroidal AntiInflammatory Drugs by Salting-Out Assisted Liquid-Liquid Extraction and Gas Chromatography-Mass Spectrometry. Journal of Chromatography A, 1218, 62406247.

[25] Liu, J., Jiang, M., Li, G., Xu, L. and Xie, M. (2010) Miniaturized Salting-Out Liquid-Liquid Extraction of Sulfonamides from Different Matrices. Analytical Chimica Acta, 679, 74-80.

[26] Quesada-Molina, C., García-Campaña, A.M. and Olmo-Iruela, M.D. (2013) IonPaired Extraction of Cephalosporins in Acetone Prior to Their Analysis by Capillary Liquid Chromatography in Environmental Water and Meat Samples. Talanta, 115, 943-949.

[27] Pesticide Risk Reduction Programme in Ethiopia. https://www.wur.nl/en/show/Pesticide-Risk-Reduction-Programme-in-Ethiopia-PR RP.htm

[28] Emana, B., Gebremedhin, H. and Regassa, N. (2010) Impacts of Improved Seeds and Agrochemicals on Food Security and Environment in the Rift Valley of Ethiopia: Implications for the Application of an African Green Revolution. Drylands Coordination Group, Oslo, Norway.

[29] Environment and Social Assessment International (2006) Pesticide Use, Accumulations and Impacts: A Case Study in the Rift Valley, Ethiopia.

[30] Mnif, W., Hassine, A.I.H., Bouaziz, A., Bartegi, A., Thomas, O. and Roig, B. (2011) Effect of Endocrine Disruptor Pesticides. International Journal of Environmental Research and Public Health, 8, 2265-2303. https://doi.org/10.3390/ijerph8062265

[31] Farajzadeh, M.A., Djozan, D. and Khorram, D. (2012) Development of a New Dispersive Liquid-Liquid Microextraction Method in a Narrow-Bore Tube for Preconcentration of Triazole Pesticides from Aqueous Samples. Analytical Chimica Acta, $713,70-78$.

[32] Fan, Y., Hu, S. and Liu, S. (2014) Salting-Out Assisted Liquid-Liquid Extraction Coupled to Dispersive Liquid-Liquid Microextraction for the Determination of Chlorophenols in Wine by High Performance Liquid Chromatography. Journal of Separation Science, 37, 3662-3668. https://doi.org/10.1002/jssc.201400869

[33] Razmara, R.S., Daneshfar, A. and Sahrai, R. (2011) Determination of Methylene Blue and Sunset Yellow in Wastewater and Food Samples Using Salting-Out Assisted Liquid-Liquid Extraction. Journal of Industrial and Engineering Chemistry, 
$17,533-536$.

[34] Zhang, J., Wu, H., Kim, E. and El-Shourbagy, T.A. (2009) Salting-Out Assisted Liquid-Liquid Extraction with Acetonitrile: A New High throughput Sample Preparation Technique for Good Laboratory Practice Bioanalysis Using Liquid Chromatography-Mass Spectrometry. Biomedical Chromatography, 23, 419-425. https://doi.org/10.1002/bmc.1135

[35] Jenkins, T.F., Miyares, P.H., Myers, K.F., McCormick, E.F. and Strong, A.B. (1994) Comparison of Solid Phase Extraction with Salting-Out Solvent Extraction for Preconcentration of Nitroaromatic and Nitramine Explosives from Water. Analytical Chimica Acta, 289, 69-78.

[36] Cai, Y., Cai, Y., Shi, Y., Liu, J., Mou, S. and Lu, Y. (2007) A Liquid-Liquid Extraction Technique for Phthalate Esters with Water-Soluble Organic Solvents by Adding Inorganic Salts. Microchimica Acta, 157, 73-79. https://doi.org/10.1007/s00604-006-0625-7

[37] Wen, Y., Li, J., Yang, F., Zhang, W., Li, W., Liao, C. and Chen, L. (2013) Salting-Out Assisted Liquid-Liquid Extraction with the Aid of Experimental Design for Determination of Benzimidazole Fungicides in High Salinity Samples by High Performance Liquid Chromatography. Talanta, 106, 119-126.

[38] Esser, H.O., Dupius, G., Ebert, E., Vogel, C. and Marco, G.J. (1976) Herbicides Chemistry, Degradation and Mode of Action. Marcel Dekker, New York, USA.

[39] European Commission, SANCO/10684/2009 (2009) Method Validation and Quality Control Procedures for Pesticide Residue Analysis in Food and Feed.

[40] Saraji, M. and Tansazan, N. (2009) Application of Dispersive Liquid-Liquid Microextract ion for the Determination of Phenylurea Herbicides in Water Samples by HPLC Diode Array Detection. Journal of Separation Science, 32, 4186-4192. https://doi.org/10.1002/jssc.200900438

[41] Wu, Q., Li, Z., Wang, C., Wu, C., Wang, W. and Wang, Z. (2011) Dispersive Solid Phase Extraction Clean-Up Combined with Dispersive Liquid-Liquid Microextraction for the Determination of Neonicotinoid Insecticides in Vegetable Samples by High Performance Liquid Chromatography. Food Analytical Methods, 4, 559-566. https://doi.org/10.1007/s12161-011-9200-x

[42] Bouri, M., Gurau, M., Salgh, R., Cretescu, I., Zougagh, M. and Rios, Á (2012) Ionic Liquids Supported on Magnetic Nanoparticles as a Sorbent Preconcentration Material for Sulfonylurea Herbicides Prior to Their Determination by Capillary Liquid Chromatography. Analytical and Bioanalytical Chemistry, 404, 1529-1538. https://doi.org/10.1007/s00216-012-6221-2

[43] Lerma-Garcia, M.J., Simo-Alfonso, E.F., Zougagh, M. and Rios, Á. (2013) Use of Gold Nano-Particle Coated Sorbent Materials for the Selective Preconcentration of Sulfonylurea Herbicides in Water Samples and Determination by Capillary Liquid Chromatography. Talanta, 105, 372-378.

[44] Quesada-Molina, C., Olmo-Iruela, M. and Garcia-Campana, A.M. (2010) Trace Deternination of Sulfonylurea Herbicides in Water and Grap Samples by Capillary One Electrophoresis Using Larg Volume Sample Staching. Analytical and Bioanalytical Chemistry, 397, 2593-2601. https://doi.org/10.1007/s00216-010-3812-7

[45] Polati, S., Bottaro, M., Frascarolo, P., Gosetti, F., Gianotti, V. and Gennaro, M.C. (2006) HPLC-UV and HPLC-MS Multiresidue Determination of Amidosulfuron, Aimsulfuron, Nicosulfuron, Thifensulfuron Methyl, Tribenuron Methyl and Azoxystrobin in Surface Waters. Analytical Chimica Acta, 579, 146-151. 
Submit or recommend next manuscript to SCIRP and we will provide best service for you:

Accepting pre-submission inquiries through Email, Facebook, LinkedIn, Twitter, etc. A wide selection of journals (inclusive of 9 subjects, more than 200 journals)

Providing 24-hour high-quality service

User-friendly online submission system

Fair and swift peer-review system

Efficient typesetting and proofreading procedure

Display of the result of downloads and visits, as well as the number of cited articles Maximum dissemination of your research work

Submit your manuscript at: http://papersubmission.scirp.org/

Or contact ajac@scirp.org 